\title{
Integrating Care: Evaluation of a Hepatitis C Clinic Co-located with Harm Reduction and Addiction Treatment Programs in a Rural Clinic
}

\author{
Susan Ruth McKenrick \\ West Virginia University, susan.mckenrick@hsc.wvu.edu
}

Follow this and additional works at: https://researchrepository.wvu.edu/etd

Part of the Public Health and Community Nursing Commons

\section{Recommended Citation \\ McKenrick, Susan Ruth, "Integrating Care: Evaluation of a Hepatitis C Clinic Co-located with Harm Reduction and Addiction Treatment Programs in a Rural Clinic" (2020). Graduate Theses, Dissertations, and Problem Reports. 7588. \\ https://researchrepository.wvu.edu/etd/7588}

This Problem/Project Report is protected by copyright and/or related rights. It has been brought to you by the The Research Repository @ WVU with permission from the rights-holder(s). You are free to use this Problem/Project Report in any way that is permitted by the copyright and related rights legislation that applies to your use. For other uses you must obtain permission from the rights-holder(s) directly, unless additional rights are indicated by a Creative Commons license in the record and/ or on the work itself. This Problem/Project Report has been accepted for inclusion in WVU Graduate Theses, Dissertations, and Problem Reports collection by an authorized administrator of The Research Repository @ WVU. For more information, please contact researchrepository@mail.wvu.edu. 
Integrating Care: Evaluation of a Hepatitis C Clinic Co-located with Harm Reduction and Addiction Treatment Programs in a Rural Clinic

Susan Ruth McKenrick

Follow this and additional works at: https://researchrepository.wvu.edu/etd

Part of the Public Health and Community Nursing Commons 
Integrating Care: Evaluation of a Hepatitis C Clinic Co-located with Harm Reduction and Addiction Treatment Programs in a Rural Clinic

Susan R. McKenrick, MSN, APRN, FNP-BC

\author{
Doctor of Nursing Practice Project Report submitted \\ to the School of Nursing \\ at West Virginia University \\ in partial fulfillment of the requirements for the degree of \\ Doctor of Nursing Practice \\ Sandra Cotton, D.N.P., Chair \\ Kesheng Wang, Ph.D. \\ Kayleigh Burner, M.S.N. \\ Emily Baldwin, B.S.N. \\ Department of Nursing
}

Morgantown, WV

2020

Keywords: Hepatitis C, HCV, Hep C, addiction, injection drug use, integrated care Copyright 2020 Susan R. McKenrick 


\begin{abstract}
Integrating Care: Evaluation of a Hepatitis C Clinic Co-located with Harm Reduction and Addiction Treatment Programs in a Rural Clinic
\end{abstract}

Susan R. McKenrick, MSN, APRN, FNP-BC

Background: West Virginia (WV) is second in the nation for cases of Hepatitis C Virus (HCV) per capita - meaning more than 24,000 residents are living with HCV. Most new cases are in young persons who inject drugs (PWID). However, the no-call, no-show rate for HCV patients coming to clinics in Morgantown is about 50\%, indicating the need to do a better job engaging them in care. Literature suggests that integrating $\mathrm{HCV}$ clinics with harm reduction and addiction treatment programs increases uptake of HCV treatment.

Objective: The overall objective was to establish an integrated HCV clinic where harm reduction and addiction treatment programs are offered to promote uptake of curative treatment by decreasing the number of no-call/no-show occurrences.

Methods: A 12-week pilot study was planned with three aims for evaluation: 1) establish the clinic and evaluate rollout with an educational presentation pre/post-test and staff satisfaction survey followed by an implementation/feasibility survey near the end of the pilot 2) track and analyze the number of appointments made and kept using an Excel log to compare with other local clinics' no-call/no-show rates 3 ) discover why patients historically have not kept appointments by use of a questionnaire.

Results: Staff knowledge was significantly increased; the clinic was started; and staff satisfaction questionnaires returned exclusively positive results, as did implementation/feasibility follow-up surveys. There was a $10 \%$ decrease in the no-call/no-show rate. However, a national pandemic and seasonal constraint may have affected enrollment, leaving only one patient eligible to complete the survey.

Discussion: While the clinic startup was successful, clinic attendance was low and reasons for lack of patient engagement remain largely unknown. However, the clinic is poised to further explore reasons for lack of engagement to halt the rising rate of HCV transmission in WV. 


\section{Acknowledgments}

There are many wonderful friends, family, colleagues, students, and acquaintances to express my gratitude to for seeing me through to this end. But first, I must give my Heavenly Father the praise and adoration He is so deserving of. Without Him, I am nothing. And it is because of the path that He set my course on that I am at this grand juncture in life. The man who saw to it that I stayed on this path and has supported me, sacrificed for me, and put up with me is beyond doubt the most Godly man I know, my husband, Mike. He proofread my papers, encouraged me when I thought I could not do one more assignment, and never fussed about the time I spent on schoolwork. I could never have done this without him.

Thanks to Chad, Becky, and Laken - our son, daughter-in-law, and granddaughter, Sarah Jonathan, and Caroline - our daughter, son-in-law, and granddaughter, and John - our youngest son. I look forward to replacing study time with spoil time! Thank each of you for your continued encouragement of this endeavor; it means more than you will ever know.

Thanks to Toni Dichiacchio for planting the seed for this project! Thanks to my project chair, Sam Cotton, as we learned and grew together. I learned to be kinder, more generous, and to laugh more with her at the helm. Thanks to Roger Carpenter who kept us both grounded in the purpose of a DNP project. Thanks to Billie Vance for making sure the project moved forward. Thanks to my mentor, FNP preceptor, colleague, and friend - Kendra Barker - who inspired me beyond measure. Thanks to Tina Antill Keener who was my sounding board and analyst when I could not figure out what to do next. Thanks to Kesheng Wang who was so patient and kind with my lack of statistical competence. Thanks to so many colleagues who checked in now and then to see how things were going. Thanks to Kayleigh Burner whose loving support is without measure. Thanks to Emily Baldwin, Laura Jones, and Milan Puskar Health Right for saying “yes”! Finally, thank you to Dani Ludwig (Appendix J) - whose tears of joy at being cured of Hepatitis C make it all worthwhile. 
Table of Contents

$\begin{array}{ll}\text { Acknowledgments } & \text { iii }\end{array}$

Table of Contents $\quad$ iv

$\begin{array}{ll}\text { Introduction } & 1\end{array}$

Background 1

General background 1

Problem Statement 3

Significance of the Problem 3

Purpose of the Project 3

Significance of Project $\quad 4$

Literature Review and Synthesis $\quad 4$

$\begin{array}{lr}\text { Theoretical Frameworks } & 10\end{array}$

Project

Description and Design of Evidence-Based Project/Intervention Plan 11

Discussion of Theoretical Framework to Support 12

Feasibility Analysis $\quad 14$

$\begin{array}{ll}\text { Impact Analysis } & 15\end{array}$

$\begin{array}{ll}\text { Resources } & 16\end{array}$

Congruence of Organization's Strategic Plan to Project 17

$\begin{array}{ll}\text { Evidence of Key Site Support } & 18\end{array}$

$\begin{array}{ll}\text { Measurable Project Objectives } & 18\end{array}$

$\begin{array}{ll}\text { Results } & 20\end{array}$

$\begin{array}{ll}\text { Discussion and Recommendations } & 22\end{array}$ 
$\begin{array}{ll}\text { Conclusion } & 24\end{array}$

$\begin{array}{ll}\text { Attainment of DNP Essentials } & 25\end{array}$

$\begin{array}{ll}\text { References } & 27\end{array}$

Table $1 \quad$ Implementation/Feasibility Survey Results 32

Table $2 \quad$ Percent of No-Call/No-Show 33

$\begin{array}{lll}\text { Figure } 1 \quad \text { Percent of No-Call/No-Show } & 34\end{array}$

$\begin{array}{ll}\text { Appendices } & 35\end{array}$

\section{Index of Appendices}

Appendix A Hepatitis C Clinic at Milan Puskar Health Right Interview Questionnaire Survey Tool $\quad 35$

Appendix B Hep C Clinic at Milan Puskar Health Right Log of Appointment Responses 36

Appendix C Letter of Support from Milan Puskar Health Right 37

Appendix D HCV Patient Labs/Studies Checklist 38

$\begin{array}{lll}\text { Appendix E } & \text { Budget } & 39\end{array}$

Appendix F Milan Puskar Health Right Hepatitis C Clinic - Getting started checklist 40

Appendix G Staff Education Pre and Post Test 41

Appendix H Staff Satisfaction Questionnaire (Anonymous) 42

Appendix I Hepatitis C Clinic at Milan Puskar Health Right Implementation/

Feasibility Survey Tool

Appendix J Permission from Danielle Ludwig $\quad 44$ 
Integrating Care: Evaluation of a Hepatitis C Clinic Co-located with Harm Reduction and Addiction Treatment Programs in a Rural Clinic

The World Health Organization (WHO, 2017) has called for the worldwide elimination of Hepatitis C Virus (HCV) by 2030. Unfortunately, according to the Centers for Disease Control (CDC, 2019), the number of HCV cases in Appalachia, and specifically in West Virginia (WV), continues to climb as sequela to the current opioid epidemic that still has a firm grip in this state. Most new cases of HCV are in young people who inject drugs (PWID) - in particular, those who share needles with infected people (CDC). The problem is further complicated by the lack of HCV patient engagement in disease treatment. Anecdotal evidence from an HCV clinic held for four hours weekly in a local health department suggests a no-call, no-show rate of about 50\% (personal communication, April 2019), and a clinic held in the Infectious Disease Department of a nearby university affiliated hospital, reports a 70\% no-show rate for new patients and a 30\% no-show rate for follow-up visits (K. Burner, personal communication, July 20, 2019). WV will only be able to meet the WHO's challenge for elimination of HCV by 2030 if providers and clinics implement a model of care that engages patients for HCV treatment and follow-up.

\section{Background}

$\mathrm{HCV}$ is a bloodborne virus that can cause systemic problems such as fatigue, coronary artery disease, endocrine diseases, depression, and more, as well as eventual liver damage that can lead to liver failure requiring transplantation, cancer, and death, according to the American Association for the Study of Liver Disease-Infectious Disease Society of America (AASLDIDSA, 2017). Because many of these symptoms are vague and not specific to any one disease, HCV often goes unrecognized and, thus, untreated - it has been dubbed "the silent killer" 
(AASLD-IDSA, 2017). According to the WHO (2017) there are an estimated 71 million persons globally living with chronic HCV infections. It is estimated that 2.4 million people are infected with HCV in the United States (US; Hofmeister et al., 2019). And, although only 3,216 cases of acute (or newly infected) HCV were reported to the CDC for the US in 2017, given that many do not have symptoms, the estimates of actual number of acute HCV cases was closer to 44,700 (CDC, 2019). It is worth noting here that, according to the CDC, up to $50 \%$ of acute infections will resolve spontaneously, without treatment. Most significant to WV is that between 2013 and 2017, the rate of HCV in WV nearly doubled - from 3.1 to 5.6 per 100,000 residents - making WV currently highest in the nation for new cases per capita (CDC).

A report by the National Viral Hepatitis Roundtable (NVHR, 2019) reveals that approximately 20,600 West Virginians are chronically infected with HCV and the population at greatest risk is young people who inject drugs (NVHR). Because there is stigma attached to PWID, there is also to HCV, as well as fear of being reported to authorities for using illegal substances. Many of those using injection drugs are either uninsured or have Medicaid as their primary insurance (NVHR) making it difficult, if not impossible, to obtain treatment for their illness. Homelessness and lack of steady employment further complicate their situations. Also complicating treatment and cure are the restrictions imposed by WV Medicaid (which influences the policies of many commercial insurers) including a 3-month sobriety requirement and that the prescriber for the curative medications must be a specialist such as gastroenterology, infectious disease, or hepatology (NVHR). Until October 1, 2019, a liver fibrosis score of F2 or greater (indicating liver damage had already occurred) was also a requirement to approve treatment- that restriction has been removed (State Of WV Department Of Health and Human Resources [WVDHHR]; Bureau For Medical Services, 2019). The cost of the oral direct acting antiviral 
(DAAs), medication which can cure $\mathrm{HCV}$, begins at around $\$ 20,000$ (NVHR) for the course of treatment. It is not feasible for most of the affected population to pay out-of-pocket for curative treatment. Co-pays for office visits and lab/radiology studies can also be cost-prohibitive. Reported WV Medicaid costs for treating HCV totaled more than \$27 million between 2014 and 2016 (WVDHHR, 2019).

\section{Problem Statement}

Worldwide elimination of HCV by 2030 is a WHO goal (WHO, 2017); but, with appointment no-call, no-show rates at HCV clinics in Morgantown ranging from $30-70 \%$, and approximately 20,600 West Virginians needing HCV treatment, it is time for healthcare providers in WV to change how this population is reached to meet their needs more effectively.

\section{Significance of the Problem}

In April of 2019 one of two HCV clinics in Morgantown (staffed by the author) closed due to an average no-call/no-show rate of $50 \%$ that resulted in a low patient volume. Another clinic in Morgantown associated with infectious disease at West Virginia University (WVU) hospitals has a higher patient volume - approximately 1000 patients over the past 3.5 years drawing from $\mathrm{WV}, \mathrm{OH}$, and $\mathrm{PA}$ - but reports a 70\% no-call/no-show rate for first time visits and $30 \%$ for follow up visits, which reflects a similar 50\% average no show rate (K. Burner, personal communication, July 20, 2019). However, nearly 20,600 West Virginians with HCV makes patient engagement an imperative.

\section{Purpose of the Project}

The overarching purpose of this project was to increase the number of people living with chronic HCV who are treated and cured of this potentially life-threatening illness by making care and treatment more accessible to the population most vulnerable - PWID. Studies have shown 
that by integrating services $(\mathrm{HCV}$, harm reduction, and addiction treatment), patient engagement is increased (Batchelder et al., 2015; Burton et al., 2019; Butner et al., 2017; Fragomeli \& Weltman, 2015; Treloar et al., 2013), so it follows that the no-call, no-show rate will decrease.

\section{Significance of the Project}

Unfortunately, despite the WHO's (2017) charge, the number of HCV cases in Appalachia, specifically in WV, continues to climb as sequela to the current opioid epidemic that still has a firm grip in this state (CDC, 2019; NVHR, 2019). Most new cases of HCV are in young PWID - particularly those who share needles with infected people (CDC, 2016). This problem is further complicated by the lack of $\mathrm{HCV}$ patient engagement in care for this disease, as evidenced by the high no-call, no-show rates in two local HCV clinics. WV will only be able to meet the WHO challenge for elimination of HCV by 2030 if providers and clinics implement models of care that engage patients for HCV treatment and follow-up.

\section{Review and Synthesis of Literature}

An initial non-exhaustive literature review was performed driven by a clinical question using the Population, Intervention, Comparison, Outcome, Time (PICOT) method (Melnyk \& Fineout-Overholt, 2015): In patients with HCV and coexisting substance use disorder (SUD), how does integrating and HCV clinic within a clinic offering harm reduction and addiction treatment programs, compared to separate appointments at another location/clinic increase the number of patients who engage in care for HCV treatment over 3 months? Using EbscoHost/CINAHL, Clinical Key, and WVU Libraries "All Databases" function, the Cochrane database was searched separately, and all included the keywords HCV, Hep C, integrated treatment, opioid treatment, and HCV treatment. After removing exact duplicates, limiting to the last 5 years, English language, and peer reviewed - the search yielded 716 results. Inclusion 
criteria was defined as: a) HCV clinics that were integrated within opioid substitution treatment clinics, b) they were community-based clinics, and c) treatment was with DAAs, and exclusion criteria defined as a) HCV treatment with older regimens that included ribavirin, interferon, or other treatment than all-oral DAAs, b) residential treatment settings, c) no integration with harm reduction or addiction treatment programs were then applied. After reviewing 75 abstracts, 11 applicable publications were included in the review.

Several studies (Batchelder et al., 2015; Burton et al., 2019; Butner et al., 2017; Treloar et al., 2013) indicated integrated treatment for HCV and drug use is effective in increasing engagement and follow-up for testing and treatment, citing reasons such as trust in providers, less stigmatized, and a non-judgmental atmosphere. A retrospective study by Stein et al. (2012) reported effectiveness of concurrent group treatment (CGT) within a methadone maintenance program. A systematic review by Pourmarzi et al. (2018) investigating community-based treatments (including one multidisciplinary model) reported several positive findings, such as trust in providers and increased accessibility, and suggested integrated services should be further considered. However, Rance and colleagues (2012) suggest in their study that integration may further stigmatize this already marginalized population.

Batchelder et al. (2015) studied psychological and behavioral changes in SUD patients (both current and former) in a primary care clinic (treating HCV) with an integrated methadone clinic. This qualitative study with 31 participants concluded that an integrated model of care has the potential to increase patient engagement in care by reducing patient perceptions of stigma and shame related to $\mathrm{HCV}$ and substance use. The study further concluded that the efficacy of the concept may have been rooted in their group treatment program wherein there was support for the shared experiences of interferon therapy-related side effects (a possible limitation of the 
study in relation to the current project as only DAA therapy is offered). Another limitation was convenience sampling. While the purpose of the study was not in alignment with the current project, the author believes it lends support for HCV clinic integration as a way to increase engagement in care.

Burton et al. (2019) demonstrated efficacy in integrating HCV care in a residential drug treatment program for Veterans. The study took place in an academic affiliated VA medical center with a 15-bed, rolling admission SUD treatment program. The facility serves a crosssection of African American (64\%), White (35.4\%), and Hispanic (0.6\%) Veterans, 54\% of whom are homeless. Many of the clients have psychiatric conditions including depression, posttraumatic stress disorder, and nearly $10 \%$ with a significant mental illness such as schizophrenia or bipolar disorder. The average length of stay was four weeks. In this setting, the SUD clinic and infectious disease clinics are located near one another, though on different floors of the main hospital. When SUD patients were discharged, a follow up program was implemented - every two weeks for those already on HCV treatment, phone calls and letters for those who missed appointments, and 3-6-month intervals for those waiting to begin treatment. All patients of the SUD program were offered HCV testing and provided with HCV education (for treatment as needed and prevention if not infected). The results revealed that uptake in initiation and follow through to completion of HCV treatment increased with the integrated model of care. Of the 597 patients screened for $\mathrm{HCV}, 74$ were diagnosed with the virus and 53 were appropriate for treatment. Of these, $48(77.59 \%)$ completed treatment.

There were notable limitations to the Burton et al. (2019) study. First, a threat to internal validity was the lack of comparative data, making it difficult to determine if there was significant improvement in uptake of treatment and follow up. Additionally, the study occurred in a VA 
facility where there are no treatment restrictions imposed, as in many state Medicaid programs (NVHR, 2017), therefore decreasing the ability to generalize results to the other populations, thus jeopardizing external validity. Despite these limitations, the study supports a clinical shift to integrating $\mathrm{HCV}$ care with addiction treatment to increase patient engagement.

A subsequent search was performed substituting "opioid treatment" with "harm reduction" in the keywords. Again, using EbscoHost/CINAHL, Clinical Key, and WVU Libraries "All Databases" function, as well as a separate Cochrane database search, the search yielded 2,921 results. However, after applying the same inclusion and exclusion criteria, only three studies were applicable. Two additional studies were included as a result of the "snowballing" search technique for a total of five more studies included in the final review.

The Brener group (2013) is discussed in further detail below and provided the most compelling support for connecting HCV treatment and harm reduction. However, in this study, the harm reduction program was across the street from an HCV clinic and had an established referral system as a means of engaging patients for the HCV clinic (Brener et al.). Furthermore, the work actually falls outside the five-year inclusion criteria parameters in an attempt to exclude studies involving older treatment therapies prior to the advent of all-oral DAAs. Regardless, their conclusions were enlightening in that an accepting, non-judgmental atmosphere of the clinic itself that was the noted as key to its success (Brener et al.). Bruggmann and Litwin (2013) provided a commentary on several models and settings for HCV and concluded that no single approach is best for all patients with HCV and suggest that there is certainly room for exploration of innovative models. The work by Kishore et al. (2019) was included for its perspective on integration with harm reduction programs as key to success and stigma as a critical barrier to engagement in treatment. Stigma as a barrier is significant in that the primary 
source of transmission is currently shared needle use among PWID, a stigmatized population (CDC, 2016). Milne et al., (2015) and Morris et al., (2017) both support the concurrent harm reduction program and $\mathrm{HCV}$ clinic model as an effective way to increase patient engagement in care and curative treatment.

Utilizing mixed methods, the Brener group (2013) evaluated a dedicated HCV clinic located across the street from a harm reduction program to easily capture referrals from the program. The clinic was defined as "integrated" and described as "holistic" and included a staff of nurses, managers, counselors, case workers, general practitioners, academics, a consultant physician, and a receptionist. In all, 24 staff members and 24 clients participated in the investigator-led interviews. Through interviews, the researchers discovered that supportive, nonjudgmental relationships between clients and providers were key to the success of the clinic. Clients and providers articulated that a holistic approach to care was central to improved outcomes (HCV treatment, symptom management, as well as general health needs). Clients were enabled to overcome a variety of barriers to care, such as fear of discrimination, feelings of stigmatization. Unfortunately, an earthquake destroyed the clinic and much of the data of the quantitative component of the study prior to the completion of the study.

A significant limitation of the work by Brener et al. (2013) is the fact that treatment was not administered in the clinic; patients were referred to the local hospital for treatment, so definitions of both internal and external validity are in question as there is no comparison group to measure improvement against and no statistical results are presented in the work.

Bruggmann and Litwin (2013) reviewed seven effective integrated models of care for HCV (including integration into addiction treatment and general practice, with community-based opioid substitution treatment, general practitioner-based models, integrating HCV in secondary 
and tertiary settings, direct observation therapy, and peer-based models). They concluded that any of these models requires good collaboration of providers, a nonjudgmental attitude among providers, and an elevated level of acceptance of the patients' life circumstances. While it was not a systematic review with statistical analysis, the literature cited supported each model (several of which are used in the current project).

Using a case study, Milne et al., (2015) describe how an integrated model of care, where $\mathrm{HCV}$ care was co-located with harm reduction and addiction therapy, as well as many other services, in an inner-city clinic, engendered trusting relationships, which the authors cite as "central" to enhancing engagement in HCV care and treatment. Over a two-year period, from 2012 through 2014, the clinic grew from 83 to 705 HCV Registry patients, and treated 101 patients with an interferon regimen during the same time period, achieving an average sustained virologic response (cure) of $81 \%$ (Milne et al., 2015). Although a case study, the Milne work adds more weight to the growing body of literature. In addition, study findings cited support issues presented in the current project, deeming the Milne group work relevant.

Overall, 10 of the articles reviewed support an integrated model of care and one suggests that it may actually increase stigma. There is a small, but strong body of literature to support a shift to an integrated model of care for HCV in the US; however, the search for supporting literature yielded primarily studies from other countries, particularly the UK and Canada. Even so, integrated clinics, such as the Evergreen Clinics, a small network of primary care clinics in Buffalo, NY (Evergreen Health, 2019) that treat SUD as well as HCV do exist. Therefore, it is reasonable to assume that such a model may be successful in $\mathrm{WV}$, where the number of infected patients is increasing in direct relation to the state's opioid epidemic (CDC, 2017). 
In February of 2020, a final literature search was performed using the same keywords and returning two additional articles appropriate for inclusion related to the topic. While neither is a research project offering data on integrating $\mathrm{HCV}$ care with harm reduction and addiction treatment, each offers valued information on the subject. Hoj et al. (2019) present a theoretical framework for study and care of the PWID population. The authors observed that uptake of treatment had not increased as expected as insurance restrictions to treatment in Canada (which reflected those still imposed in many states in the US) were removed. They questioned why there was an apparent gap in care and believed there was a need for "deliberate" theory to support research and direct the delivery of care to PWID. Interestingly, this group also utilized "candidacy", among other theories and frameworks, to shape their own framework; the final product is built squarely on the theory of candidacy.

An editorial by Marshall et al. (2019) emphasizes the need to change the approach to care of HCV patients who inject drugs. They suggest not only integrating care in terms of location, but in terms of care provider - recommending that addiction medicine specialists are well-poised to facilitate care of HCV in PWID as part of their addiction treatment programs. Although one of the authors (Treloar) disclosed a conflict of interest (paid speaker's bureau), the emphasis of this article is the integrated care model. Both writings support integrated models of care and treatment and therefore were included in the current review.

\section{Theoretical Frameworks}

Two frameworks were chosen to direct this project - Roger's Diffusion of Innovations and Candidacy. Rogers (2003) explains that Diffusion of Innovations is about the way a new idea is communicated to others and perceived by others. According to Rogers, an idea may or may not necessarily be "new", as in never thought of before, but it becomes "new" as someone has a 
new awareness of it with a plan to put it into action because the status quo is not working. The Candidacy framework, as presented by Tookey et al. (2018) speaks to an individual's sense of worth or eligibility of treatment for an illness and suggests six stages that may be involved are a) Identification of candidacy b) Navigation of services c) Permeability of services d) Appearance at services e) Adjudication by healthcare f) Offers of and resistance to services. How these frameworks support the project is discussed later.

\section{Project}

\section{Evidence-Based Project/Intervention Plan}

The project intervention involved strategically integrating an HCV clinic within a local free primary care clinic, Milan Puskar Health Right (MPHR), that offers both a harm reduction program and addiction treatment. The overarching goal is to increase engagement in care by those infected with HCV by locating the clinic in an environment where the population at highest risk for HCV (PWID) would feel comfortable and welcomed. The hours of operation for the clinic coincided with the harm reduction program held on Friday afternoons from 1:00 PM until 4:30 PM. The timing offers two benefits: 1) Patients who are already coming for the harm reduction program are able to schedule appointments for HCV care without making an extra trip to MPHR and 2) Clients of the harm reduction program who are screened and test positive (via rapid testing) can be introduced to the provider to establish an immediate therapeutic relationship which will promote active engagement in care (appointments made and kept.) A Nurse Practitioner (the author), who has trained extensively in HCV treatment and regularly attends Project ECHO (Extension for Community Healthcare Outcomes) HCV programming for continuing support, is the care provider for the clinic. The project received WVU Internal Review Board (IRB) approval in mid-January. The author had been working closely with key 
staff at MPHR, so the clinic was prepared for almost immediate startup upon IRB approval. The plan was for the clinic to be held and data collected for 12 weeks. Planned data collection included a deidentified patient questionnaire to discover themes for lack of engagement in care (Appendix A) and a deidentified Excel log to track appointments made, kept, cancelled, rescheduled, and no-call, no-show (Appendix B).

\section{Theoretical Frameworks Discussion}

The status quo for HCV treatment is primary care, infectious disease specialty, or gastroenterology. According to Rogers (2003), there are five phases an innovative plan to change or improve on the status quo goes through - knowledge, persuasion, decision, implementation, and confirmation. It was during the "knowledge" phase it became clear that the current HCV clinic was not well attended at the Health Department and the idea was born to integrate HCV care with drug addiction treatment. After an initial plan to integrate the clinic into a local addiction treatment center was found to be unfeasible, the author continued to pursue other options, leading to the opportunity to integrate $\mathrm{HCV}$ care with harm reduction services and addiction treatment. The "persuasion" phase occurred when a review of literature affirmed placing the clinic where it would be more easily accessed by those at the highest risk - those who are injection drug users. The "decision" phase is when the choice to adopt or reject a new idea in this case, to adopt - is made. This phase includes buy-in from stakeholders. When the author approached MPHR key administrative personnel about integrating an HCV Clinic with existing harm reduction and addiction treatment, the response was unreservedly positive.

"Implementation" is the next phase where a new idea is put into action and outcomes are measured to see if it is effective. January 17, 2020 was the first day of clinic. Finally, the plan 
itself is confirmed or adopted - either it works and continues, works but needs adjusted, or did not work and is abandoned.

The Candidacy framework, as presented by Tookey et al. (2018) speaks to an individual's sense of worth or eligibility of treatment for an illness and suggests six stages that may be involved are:

- Identification of candidacy - is the patient eligible, do they even know they need care? Do those infected with HCV know there is a cure? HCV has been referred to as a "silent killer". Those who are infected often do not realize they have the disease as symptoms can mimic other diseases and damage to the liver may not be realized for many years after exposure.

- Navigation of services - what is their health literacy, can they identify and reach the proper services? Meeting patients where they are, in a non-threatening environment where they already access other services will mitigate the problem of poor health literacy and uncertainty of where to get help for this disease.

- Permeability of services - do they feel stigmatized or discriminated against, and is the environment hostile or uninviting? Literature suggests that the stigma of HCV inhibits use of mainstream services (Treloar et al., 2013). Holding the clinic where they are already accessing primary care, addiction treatment, and harm reduction services lessens those feelings.

- Appearance at services - are patients able to effectively communicate their needs to providers? HCV symptoms can be vague and mimic other conditions, so patients may need prompted to elicit an accurate picture of their current health status. 
- Adjudication by healthcare - are providers following the care guidelines or does personal bias interfere? The new DAA medications are expensive and insurers have been reluctant to provide coverage if patients infected with HCV have no liver damage yet or are still injecting drugs. Thankfully, many insurers have begun to lift these restrictions, along with the specialty provider/consult requirement.

- Offers of and resistance to services - do patients fully understand their treatment options, the costs, and other treatment-related issues or do they resist offers for testing and treatment out of fear or lack of knowledge? Patients are not always aware of the newer oral DAA curative treatments for $\mathrm{HCV}$ or they do not realize the side effect profile is not severe like people they may know had treatment with interferon and/or ribavirin, so they avoid treatment out of fear of the side effects that they have heard about.

These stages and concepts are the framework for understanding this patient population's particular need to be treated for $\mathrm{HCV}$ in a non-judgmental, compassionate, friendly environment where education is provided about how to take care of themselves and their loved ones, prevent transmission of the disease, and the treatment options that are available to cure the virus.

\section{Feasibility Analysis}

With approximately 20,600 West Virginians infected with HCV (NVHR, 2019), more HCV clinics are needed, not fewer. This quality improvement project was aimed at increasing patient engagement by establishing an integrated HCV clinic within a local free clinic, coincident with harm reduction and opioid addiction programs to improve ease of access to HCV care. Studies have shown that integrated HCV and addiction treatment show an increase in patient engagement in care (Batchelder et al., 2015; Burton et al., 2019; Butner et al., 2017; Treloar et al., 2013) - further strengthening the presence of the HCV Clinic at MPHR. Meetings with the 
executive director, nursing director, and author began in late August of 2019 to discuss plans for the HCV Clinic. These meetings culminated in a signed letter of support for the project from the executive director of MPHR (Appendix C).

Looking ahead at sustainability - steps have already been taken for the author to become credentialed to be able to bill for services pending negotiation of a WVU clinical faculty practice site allowing the author (who is a WVU School of Nursing faculty) to continue the work.

The author has developed an HCV protocol checklist for other/new providers to follow and will continue to revise and share this as needs arise (Appendix D). Opportunities for expansion at MPHR include having a clinic that runs concurrent with the Wednesday harm reduction time. They also have a mobile harm reduction unit that may have potential for reaching other counties. Ideally, WV Medicaid would remove the current restrictions to treatment so that primary care providers can treat all uncomplicated patients without referral to specialty providers, paving the way for all providers at MPHR to become educated and confident to treat $\mathrm{HCV}$ as an integral part of primary care. The author developed a policy brief to share with key stakeholders at WV Medicaid with the intent to affect a change in policy that would remove HCV treatment restrictions. In the long term, if the WHO (2017) goal of complete elimination by 2030 is met, the clinic would hopefully then become obsolete.

\section{Impact Analysis}

The primary expected impact will be an increase in the number of people with HCV who are treated and cured of the disease. Integrating the HCV clinic with harm reduction services means the clinic will have greater visibility to the population at highest risk for the disease. If this pilot is successful and the model is imitated elsewhere, it could contribute significantly to the WHO goal of worldwide elimination of HCV by 2030 (WHO, 2017). As much of what is written 
on a model where $\mathrm{HCV}$ care coincides with harm reduction services and/or addiction treatment comes from abroad, there is opportunity to publish this work, as well as writing to inform other healthcare providers with similar no-show rates of an innovative effective model of care to implement in the US. It is said, "Success Breeds Success" - to those who are passionate about bringing curative treatment to HCV patients and are in search of innovative ways to capture this population, success of this pilot project may be attractive.

\section{Resources}

Personnel needs. Upon discussion with administrative personnel at MPHR prior to clinic startup it was determined that the current staffing level for Friday afternoon was adequate to manage any additional patient needs generated by the clinic, including check-in, rooming, and lab draws. Clinic staff present on Friday afternoon includes an RN, LPN, two medical assistants, and a receptionist. No additional personnel were required for clinic the function.

Budget. The total anticipated amount needed for this project was $\$ 3,275$. At the time the budget was developed, the author hoped to obtain a grant from the West Virginia Clinical \& Translational Science Institute (WVCTSI); however, the timing for grant submission/award did not coincide with the project timing and the grant was not pursued. Funding for the project came through donations. The actual cost of clinic implementation was \$3038, which was \$207 under budget and \$32 under the total income allotted for the project. The budget balance sheet with explanations is presented in Appendix E.

Technology. MPHR has several laptop computers available for provider use to chart using a web-based electronic health record (EHR). The author was named on the EHR license as a provider at no additional cost to the organization. No further technology needs were identified 
during the pilot period, apart from the author's laptop to track appointments using an Excel spreadsheet and IBM SPSS software to calculate test statistics for project evaluation.

\section{Congruence of Organization's Strategic Plan/Mission to Project}

Milan Puskar Health Right's Mission Statement:

Health Right is a primary care clinic that provides health care at no cost to uninsured or underinsured low-income residents of North Central WV. Health Right promotes health through direct service, education, and advocacy.

The mission of MPHR aligns with the goals of this project well. Housed in MPHR is a syringe access/harm reduction program known as the LIGHT program. LIGHT is an acronym for Living In Good Health Together. Shared needles by PWID is the primary transmission route for HCV in WV today (NVHR, 2017). Timing the HCV clinic to run concurrently with the LIGHT program could minimize fear of stigma, promote patient trust, and improve access to care. MPHR currently hosts several other specialty clinics such as women's health, diabetes care, and HIV testing, in addition to mental health services, homeless services, addiction treatment, and primary health care. The founding premise of MPHR is that every person has a right to health care regardless of their insurance status or ability to pay (GuideStar, 2017). The purpose of the project is to increase the number of people cured of $\mathrm{HCV}$ in $\mathrm{WV}$, and currently the population at greatest risk is people who inject drugs - many of whom are either uninsured or underinsured. The project is also in line with WVU's mission, vision, and values of service to the community and state as a land-grant institution. 


\section{Evidence of Key Site Support}

A letter of support was obtained by the director of MPHR and is included as an appendix item as noted previously. Positive, welcoming attitudes and helpfulness of the staff at MPHR were also evidence of their support for integrating the HCV Clinic.

\section{Measurable Project Objectives}

The overarching goal of the project is to increase patient engagement in care for HCV. To that end, the three aims to evaluate this project were to 1) establish an integrated HCV clinic at a MPHR to run concurrently with their LIGHT program on Friday afternoons, 2) evaluate the efficacy of the plan, and 3) explore the reasons patients miss appointments.

Aim 1. Establishment of the HCV clinic at MPHR was measured through three objectives. First, completing a checklist of items to carry out for the creation of the clinic. The checklist was kept simple and is found in Appendix F. All checklist items were developed to ease assimilation of the clinic into the current workflow. Each was accomplished prior to the first patient care day. Second, a "Lunch and Learn" educational program, attended by a mix of APRNs, RNs, MAs, social workers, counselors, and office staff, took place two days prior to the first clinic day was evaluated using a pre/post-test (Appendix G) taken by all 15 attendees prior to and following the program. An anonymous staff satisfaction evaluation survey (Appendix $\mathrm{H}$ ) was also used to evaluate the program. Using IBM SPSS, a paired-samples t-test was planned to evaluate the impact of the educational presentation on staff knowledge of HCV care and services.

A third objective, concerning implementation/feasibility, was added later to the pilot with an IRB amendment to enhance the evaluation of clinic startup. An anonymous survey (Appendix I) was administered via Qualtrics near the end of the 12-week pilot period to assess MPHR staff perception of the value, need for, and rollout of the clinic. Development of the survey was 
guided by Bowen et al. (2009) where eight areas of focus for feasibility studies were identified. The areas this survey focused on were acceptability - evaluated by satisfaction and intent to continue use, demand - evaluated by fit within the organizational culture, implementation measured by degree and success or failure of execution, practicality - measured by the efficiency and quality of implementation, integration - measured by the perceived fit with existing infrastructure and perceived sustainability, expansion - measured by fit with organization goals and culture and/or positive or negative effects on organization, , and limited efficacy - measured by maintenance of changes from initial change.

Finally, clinic startup was evaluated periodically using the Plan-Do-Study-Act (PDSA) method as described by the Institute for Healthcare Improvement (IHI, 2020). PDSA cycles have been developed as a methodical system for making and evaluating changes on a small scale (IHI). PDSA cycles directed improvements over the course of the project (IHI).

Aim 2. The planned evaluation of efficacy of the intervention to increase engagement in HCV care was to maintain a deidentified Excel $\log$ (Appendix B) of appointments made, kept, called to cancel, called to reschedule, or no-call/no-show and compare findings of no-call, noshow rates at two other clinics in Morgantown (one hospital-based, one located at a health department).

Aim 3. The third aim was to discover reasons for the lack of engagement in care among HCV patients using a Likert survey style questionnaire (Appendix A) with a list of 15 possible reasons for missed appointments such as transportation problems, forgot, fear, dissatisfaction with previous care/treatment to value on a scale of 1-5 how significant the items were with $1=$ Not at all and $5=A$ lot. A text option was included to write in reasons not listed. There was also a free text question to elicit what, if anything, the healthcare system could do to help them keep 
their appointments. Descriptive statistics were planned to reveal if a trend toward any reason/s existed. Such information could then be used to explore ways to mitigate appointment barriers. Any demographic data obtained would enrich the main project findings.

\section{Results}

Aim 1. The clinic startup checklist of items to accomplish prior to the first patient day helped ensure that the staff and provider were prepared with the proper paperwork, supplies, equipment, credentialing, and general readiness. The objective of increasing staff knowledge about HCV was met through the educational "Lunch and Learn" program. Providing a light lunch for participants helped create a warm learning environment. There was a significant increase in the Staff Education test scores from pre-test $(M=5.13, S D=1.13)$ to the post-test $(M$ $=6.67, S D=0.62), t(14)=-5.996, \mathrm{p}=<.001$ (two-tailed). The mean change in scores was -1.53 with a $95 \%$ confidence interval ranging from [-2.08 to -.98]. The four-question Likert survey designed to evaluate staff readiness and confidence was completed by 11(73\%) attendees. The scale ranged from $1=$ Very satisfied to $5=$ Very dissatisfied. For item 1 - The educational program helped me feel prepared for this clinic - the mean score was $1.09(S D=.302)$, for item 2 - The Phone Triage flyer helped me answer questions when patients called - the mean was $1.09(S D=.302)$, the third item - The education program helped me feel more confident about using patient assistance programs for HCV medications - had a mean of $1.18(S D=.405)$, and the final item - The learning objectives (disease process, fielding phone questions, anticipated lab and imaging tests, and assistance programs) were met - had a mean of 1.09 (SD .302).

There were 13 respondents $(n=13)$ to the implementation/feasibility survey including 11 females and two males with the average age range 35 to 45 years old. Sixty-two percent (62\%) of the respondents had worked at MPHR for less than two years, 23\% 2-4 years, and 15\% longer 
than six years with $85 \%$ of the respondents being full time employees and $15 \%$ part-time. The participants were a mix of nursing staff, office staff, providers (MD, PA, NP), case managers/social workers, and "others". Ten (80\%) of the 13 attended the prestart "Lunch and Learn" session. The remaining items were based on a Likert scale of $1=$ Strongly agree, $2=$ Somewhat agree, 3 = Neither agree nor disagree, $4=$ Somewhat disagree, $5=$ Strongly disagree, and a sixth option $=$ Not applicable. The results shown in Table 1 indicate the staff's perceived need and support for clinic.

The Plan stage of the cycle (plan for change) led to clinic readiness for the first patient day on January 17,2020 . In the Do stage, the clinic began seeing patients on a small scale with one - two patients scheduled per clinic session. In the Study phase the author noted what worked well and what did not regarding workflow and referral, which led to changes in lab testing ordered by primary care providers who expressed some confusion about the algorithm for testing. In the Act phase a new, clearer algorithm was developed and made available to all MPHR providers by posting in the providers' workroom. The author elicited provider feedback over the next couple of weeks of clinic and all expressed satisfaction with the improved testing algorithm. No other issues were identified with subsequent PDSA cycles.

Aim 2. Over the nine weeks that the clinic was able to see patients, seven were scheduled, two patients were seen, two did not call/show for their appointments, one cancelled by phone, two other patients were found to have cleared the virus spontaneously and were notified by their primary care providers of this finding and were removed from the schedule for a final $n=5$. While this is a small sample, there is some evidence of efficacy in that there was only a 40\% No-call/No-show rate during this time as depicted in Figure 1 and Table 2. Weather 
affected the clinic throughout the winter, and the onset of the COVID-19 pandemic disrupted the final weeks of the project.

Aim 3. Of the two patients seen in clinic, only one qualified to complete the survey exploring reasons for missed appointments. The second patient had been seen by a volunteer prior to IRB approval for the project and was there for treatment follow-up. However, some of the answers on the survey collected support the reasons for establishing this clinic $-\mathrm{a}$ score of 3 was assigned to "Felt judged or discriminated against" and 5 for "Fear". Other reasons included "Forgot" and "Copay was too high", which were both scored a 4. Concerns written in the "Other" box included the cost of the medication and concern that re-treatment would not be an option if infected again. Although survey data was only available from one patient, an " $n$ of 1 " in clinical care/quality improvement may be a useful starting place to begin to understand complex issues affecting this challenging population.

\section{Discussion and Recommendations}

The theoretical frameworks of Diffusion of Innovations (Rogers, 2003) and Candidacy (Tookey et al., 2014) supported this project well. While much is written about this model in the UK and Australia, (Batchelder et al., 2015; Burton et al., 2019; Butner et al., 2017; Treloar et al., 2013), there is little about it in the US. Adopting this care model and reproducing it in WV has the potential to impact the broader US population as it moves toward elimination of HCV. The Tookey group (2014) Candidacy framework guides providers to ask good questions and be sensitive to the unique needs of the population at greatest risk for HCV - PWID. For example, an older patient may have had treatment prior to the new DAAs and not be aware that there are new drugs in pill form, taken once daily for eight to twelve weeks that have few side effects. That patient may be reticent to begin treatment based on past experience and lack of knowledge - they 
may be resistant to services (the last stage of Candidacy). Sensitive providers can overcome the resistance with education and counseling to guide patients toward readiness for treatment.

The post-test analysis showed a significant increase in staff knowledge about HCV and the functions of the clinic over the pretest; however, they may have benefited from further discussion of the disease progression, and more in-depth discussion of a testing to treatment algorithm - particularly for care providers as there were lingering questions about what labs to order and when. It might have been better to hold two sessions - one for clinical staff and one for providers as each group had discreet questions and needs. The PDSA cycle revealed the lab testing algorithm issue so it could be remedied quickly.

As previously noted, weather and the onset of the COVID-19 may have been a factor in patient referrals and appointments as MPHR was shifting to seeing only urgent needs patients (which would not typically include HCV patients). Further impacting the case load was that a few more patients that providers had planned to refer were found to have spontaneously cleared the virus when lab tests in preparation for referral was obtained, so there was no need to refer. Despite this, the no-call/no-show rate was shown at 9 weeks of clinic to be $40 \%$ (as previously discussed, see Table 2 and Figure 1).

Another possible barrier for this clinic is the time frame. The clinic is only held once per week on Friday afternoons, which could conflict with work or other schedules. Expanding to include other appointment options may help increase attendance. The LIGHT harm reduction program has a mobile unit that serves other counties which may have potential for screening and $\mathrm{HCV}$ clinic referral. Another option might be to make the clinic schedule flexible - meaning that the clinic is open from 1-4:30, and HCV patients can come at the time most convenient for them. 
The mobile unit and flex scheduling options are novel approaches that were not noted in the literature reviewed for the project.

The project should be continued (in fact, there was concern expressed by staff about what was to happen to the clinic at the end of the pilot), becoming part of the clinic standard of care for PWID who also have HCV. MPHR providers see patients with $\mathrm{HCV}$ often. Establishing a trusted presence is key to growing the clinic. Key stakeholders in the clinic - the director, staff, providers - have expressed verbally and by survey responses that they believe in the value of an HCV clinic on site. The clinic holds potential for further study to hone in on reasons this population tends to have a high no-call/no-show rate, as well as demonstrate the efficacy of an integrated clinical model of care by the volume of patients over a longer period. MPHR is well suited for continuation and should serve WV well as a model for HCV care.

\section{Conclusion}

Although the clinic startup was successful, and staff HCV knowledge improved, clinic attendance was minimal and additional reasons for lack of patient engagement remain unknown. With time to establish a trusted presence with the patient population, warmer weather, abatement of COVID-19, and increasing referrals from the MPHR primary care providers, the integrated model of HCV care there has the potential to set the pace for similar models across the state. The clinic is poised to explore and improve care engagement in hopes of halting WV's and the nation's rising $\mathrm{HCV}$ transmission rate. 


\section{Attainment of the Essentials of Doctoral Education for Advanced Practice}

The eight Essentials of Doctoral Education for Advanced Practice are specified learning outcomes and objectives put forth for DNP students by the American Association of Colleges of Nursing (ANCC, 2006).

Essential I: Scientific Underpinnings for Practice was met using two theoretical frameworks to support the clinic integration and qualitative research to explore reasons for lack of engagement in care among PWID who have HCV.

\section{Essential II: Organizational and Systems Leadership for Quality Improvement and}

Systems Thinking objectives were met through the development and implementation of this project - a care delivery approach was found lacking, but, through communication with Health Right leadership, a plan to improve delivery of health care to hep c patients was developed. The project required a feasibility and needs assessment study and the development of a budget. Finally, the project demonstrates sensitivity to an organizational culture that is already sensitive to the targeted population.

\section{Essential III: Clinical Scholarship and Analytical Methods for Evidence-Based Practice} were met through performing a literature review and using the information to support a systems change in the way the needs of HCV patients are met. The creation and implementation of a qualitative interview/survey to explore the reasons for missed appointments in this population, a quantitative data analysis of appointment no-call, no-shows compared to two other area Hep C clinics, and dissemination of these findings through project presentation and publication will complete this DNP essential.

\section{Essential IV: Information Systems/Technology and Patient Care Technology for the} Improvement and Transformation of Health Care is met through the use of an excel spreadsheet 
to track appointments made and kept or not kept for analysis, as well as the use of statistical software (IBM SPSS) to assist in that analysis to demonstrate significance.

Essential V: Health Care Policy for Advocacy in Health Care was met through the preparation and presentation of a health policy brief poster on the cost of Hep C at the WV Nurse Policy Day in Charleston, WV in 2019, and by presenting the project in poster form at the 2020 Nurse Policy Day.

\section{Essential VI: Interprofessional Collaboration for Improving Patient and Population Health}

Outcomes is being met through interprofessional collaborations with HCV experts (infectious disease expert NPs and physicians), social workers attuned to the unique needs of this population, and others through personal communication, online interaction via Project ECHO (Expanding Capacity for Health Outcomes), and participation in the West Virginia Hepatitis Academic Partners (WVHAMP) project as both a presenter and participant to advance primary care providers as expert (and unrestricted) HCV treatment prescribers.

\section{Essential VII: Clinical Prevention and Population Health for Improving the Nation's}

Health is met through integrating a Hep C clinic to coincide with a harm reduction program with the intent of promoting engagement in care for hep $\mathrm{C}$ which will increase the number of persons cured of this disease and reduce the risk of transmission.

Essential VIII: Advanced Nursing Practice was met through creating new patient and professional relationships that promoted placement of the integrated clinic to improve patient outcomes. Establishing this clinic required thinking at a higher level in order to develop the protocols and systems that make the clinic function in a way that best meets the needs of the patients and organization. 


\section{References}

American Association for the Study of Liver Disease-Infectious Disease Society of America. (2019). HCV guidance panel: Recommendations for testing, managing, and treating hepatitis $C$. http://hcvguidelines.org/

American Association of Colleges of Nursing. (2006). The essentials of doctoral education for advanced nursing practice. Washington, DC: Author. https://www.aacnnursing.org /Portals/42/Publications/DNPEssentials.pdf

Batchelder, A., Peyser, D., Nahvi, S., Arnsten, J., \& Litwin, A. (2015). "Hepatitis C treatment turned me around:" Psychological and behavioral transformation related to hepatitis c treatment. Drug and Alcohol Dependence, 153, 66-71. https://doi.org/10.1016 j.drugalcdep.2015.06.007

Bowen, D. J., Kreuter, M., Spring, B., Cofta-Woerpel, L., Linnan, L., Weiner, D., Bakken, S., Kaplan, C. P., Squiers L., Fabrizio, C., \& Fernandez, M. (2009). How we design feasibility studies. American Journal of Preventive Medicine, 36(5), 452-457. https://doi.org/10.1016/j.amepre.2009.02.002

Brener, L., Gray, R., Cama, E. J., \& Treloar, C. (2013). “Makes you wanna do treatment”: Benefits of a hepatitis $\mathrm{C}$ specialist clinic to clients in Christchurch, New Zealand. Health \& Social Care in the Community, 21(2), 216-223. https://doi.org/10.1111/hsc.12009

Bruggmann, P., \& Litwin, A. H. (2013). Models of care for the management of hepatitis c virus among people who inject drugs: One size does not fit all. Clinical Infectious Diseases, 57(suppl_2), S56-S61. https://doi.org/10.1093/cid/cit271 
Burton, M., Voluse, A., \& Anthony, V. (2019). Integrating comprehensive hepatitis c virus care within a residential substance use disorder treatment program. Journal of Substance Abuse Treatment, 98, 9-14. https://doi.org/10.1016/j.jsat.2018.11.008

Butner, J., Gupta, N., Fabian, C., Henry, S., Shi, J., \& Tetrault, J. (2017). Onsite treatment of HCV infection with direct acting antivirals within an opioid treatment program. Journal of Substance Abuse Treatment, 75, 49-53.http://dx.doi.org/10.1016/j.jsat.2016.12.014

CDC, Division of Viral Hepatitis, National Center for HIV/AIDS, Viral Hepatitis, STD, and TB Prevention. (2016). Viral hepatitis surveillance United States. https://www.cdc.gov/hepatitis/hcv/hcvfaq.htm\#section1

CDC (2019). Surveillance for viral hepatitis - United States, 2017, originally released on September 10, 2019. https://www.cdc.gov/hepatitis/statistics/2017surveillance/index.htm Evergreen Health. (2019). Buffalo, NY.https://www.evergreenhs.org/

Fragomeli, V., \& Weltman, M. (2015). Addressing viral hepatitis in the opiate substitution setting: An integrated nursing model of care. Journal of Gastroenterology and Hepatology, 30, 6-11. https://doi.org/10.1111/jgh.12864

GuideStar by Candid. Milan Puskar Health Right. (2017). https://www.guidestar.org/profile/31$\underline{1118673}$

Hofmeister, M. G., Rosenthal, E. M., Barker, L. K., Rosenberg, E. S., Barranco, M. A., Hall, E. W., Edlin, B. R., Mermin, J., Ward, J. W., \& Ryerson, A. B. (2019). Estimating prevalence of hepatitis C virus infection in the United States, 2013-2016. Hepatology, 69(3), 1020-1031. https://doi.org/10.1002/hep.30297 
Høj, S., Jacka, B., Minoyan, N., Artenie, A., \& Bruneau, J. (2019). Conceptualising access in the direct-acting antiviral era: An integrated framework to inform research and practice in HCV care for people who inject drugs. International Journal of Drug Policy. 72, 11-23. https://doi.org/10.1016/j.drugpo.2019.04.001

Institute for Healthcare Improvement (IHI). (2019). Plan-Do-Study-Act (PDSA). http://www.ihi.org/resources/Pages/HowtoImprove/ScienceofImprovementTestingChang $\underline{\text { es.aspx }}$

Kishore, S., Hayden, M., \& Rich, J. (2019). Lessons from Scott County - progress or paralysis on harm reduction? New England Journal of Medicine, 380(21), 1988-1990. https://www.nejm.org/doi/10.1056/NEJMp1901276

Marshall, A. D., Madden, A., \& Treloar, C. (2019). Enhancing engagement in hepatitis C care among people who inject drugs. Addiction, 114(12), 2104-2106. https://doiorg.www.libproxy.wvu.edu/10.1111/add.14698

Milne, R., Price, M., Wallace, B., Drost, A., Haigh-Gidora, I., Nezil, F. A., \& Fraser, C. (2015). From principles to practice: Description of a novel equity-based HCV primary care treatment model for PWID. Expanding access to prevention, care and treatment for hepatitis C virus infection among people who inject drugs. International Journal of Drug Policy, 26(10), 1020-1027. https://doi.org/10.1016/j.drugpo.2015.07.009

Morris, L., Smirnov, A., Kvassay, A., Leslie, E., Kavanagh, R., Alexander, N., Davey, G., Williams, O., Gilks, C., \& Najman, J. (2017). Initial outcomes of integrated communitybased hepatitis c treatment for people who inject drugs: Findings from the Queensland Injectors' Health Network. International Journal of Drug Policy, 47, 216-220. https://doi.org/10.1016/j.drugpo.2017.05.056 
National Viral Hepatitis Roundtable, Harvard Law School, Center for Health Law and Policy Innovation. (2019). Hepatitis C: The state of Medicaid access. 2017 National summary report. https://stateofhepc.org/

Pourmarzi, D., Hall, L., Hepworth, J., Smirnov, A., Rahman, T., \& FitzGerald, G. (2019). Clinical effectiveness, cost effectiveness and acceptability of community-based treatment of hepatitis c virus infection: A mixed method systematic review. Journal of Viral Hepatitis, 26(4), 432-453. https://doi.org/10.1111/jvh.13045

Rance, J., Newland, J., Hopwood, M., \& Treloar, C. (2012). The politics of place(ment): Problematising the provision of hepatitis $\mathrm{c}$ treatment within opiate substitution clinics. Social Science \& Medicine (1982), 74(2), 245-53. https://doi.org/10.1016/j.socscimed.2011.10.003

Rogers, E. (2003). Diffusion of innovations (5th ed.). New York: Free Press.

State Of West Virginia Department of Health and Human Resources Bureau for Medical Services (2019). Office of pharmacy services prior authorization criteria for chronic hepatitis c virus (hcv) therapy. v2019.3b. https://dhhr.wv.gov/bms/BMS \%20Pharmacy/Documents/Hepatitis\%20C\%20Criteria\%20 v2020.1a.pdf

Tookey, S., Renzi, C., Waller, J., von Wagner, C., \& Whitaker, K. L. (2018). Using the candidacy framework to understand how doctor-patient interactions influence perceived eligibility to seek help for cancer alarm symptoms: A qualitative interview study. BioMed Central Health Services Research, 18(1). https://doi.org/10.1186/s12913-018-3730-5 
Treloar, C., Rance, J., Grebely, J., \& Dore, G. (2013). Client and staff experiences of a colocated service for hepatitis c care in opioid substitution treatment settings in New South Wales, Australia. Drug and Alcohol Dependence, 133(2), 529-534. https://doi.org/10.1016/j.drugalcdep.2013.07.023

West Virginia University. (2020). https://www.wvu.edu/about-wvu/mission

World Health Organization. (2017). Global Hepatitis Report, 2017. Geneva: Switzerland. https://apps.who.int/iris/bitstream/handle/10665/255016/9789241565455eng.pdf;jsessionid=661A7B98F5A5F96676BDCBEE2386592C? sequence $=1$ 
Table 1.

Implementation/Feasibility Survey Results

Descriptive statistics

\begin{tabular}{|c|c|c|c|c|c|}
\hline & $n$ & Minimum & Maximum & Mean & $\begin{array}{r}\text { Std. } \\
\text { Deviation } \\
\end{array}$ \\
\hline $\begin{array}{l}\text { The HCV clinic fits well with the } \\
\text { mission of MPHR }\end{array}$ & 13 & 1 & 1 & 1.00 & 0.000 \\
\hline $\begin{array}{l}\text { There is a need for an HCV clinic at } \\
\text { MPHR }\end{array}$ & 13 & 1 & 1 & 1.00 & 0.000 \\
\hline $\begin{array}{l}\text { The HCV clinic at MPHR interferes } \\
\text { with other services offered here }\end{array}$ & 13 & 4 & 6 & 5.00 & 0.408 \\
\hline $\begin{array}{l}\text { The transition to having an HCV } \\
\text { clinic located at MPHR has been a } \\
\text { smooth one }\end{array}$ & 13 & 1 & 3 & 1.46 & 0.660 \\
\hline $\begin{array}{l}\text { There is no need for an HCV clinic at } \\
\text { MPHR }\end{array}$ & 13 & 5 & 5 & 5.00 & 0.000 \\
\hline $\begin{array}{l}\text { The HCV clinic is an added burden to } \\
\text { the staff }\end{array}$ & 13 & 3 & 6 & 4.85 & 0.689 \\
\hline $\begin{array}{l}\text { I have or plan to refer patients to the } \\
\text { HCV clinic at MPHR }\end{array}$ & 13 & 1 & 6 & 1.54 & 1.450 \\
\hline $\begin{array}{l}\text { The education program provided } \\
\text { before the HCV clinic opened helped } \\
\text { me understand the need for it at } \\
\text { MPHR }\end{array}$ & 13 & 1 & 6 & 2.77 & 2.315 \\
\hline $\begin{array}{l}\text { The HCV clinic has increased } \\
\text { congestion in the waiting room }\end{array}$ & 13 & 3 & 6 & 4.92 & 0.641 \\
\hline The HCV clinic is valuable to MPHR & 13 & 1 & 2 & 1.08 & 0.277 \\
\hline $\begin{array}{l}\text { The education program provided } \\
\text { before the HCV clinic opened helped } \\
\text { prepare me for my role }\end{array}$ & 15 & 1 & 6 & 3.13 & 2.200 \\
\hline
\end{tabular}


Table 2.

Percent of No-call/No-show

\begin{tabular}{|c|c|c|c|c|c|}
\hline & & & & Valid & Cumulative \\
\hline & & Frequency & Percent & Percent & Percent \\
\hline \multirow[t]{3}{*}{ Valid } & Yes & 2 & 40.0 & 40.0 & 40.0 \\
\hline & No & 3 & 60.0 & 60.0 & 100.0 \\
\hline & Total & 5 & 100.0 & 100.0 & \\
\hline
\end{tabular}


Figure 1.

Percent of No-call/No-show

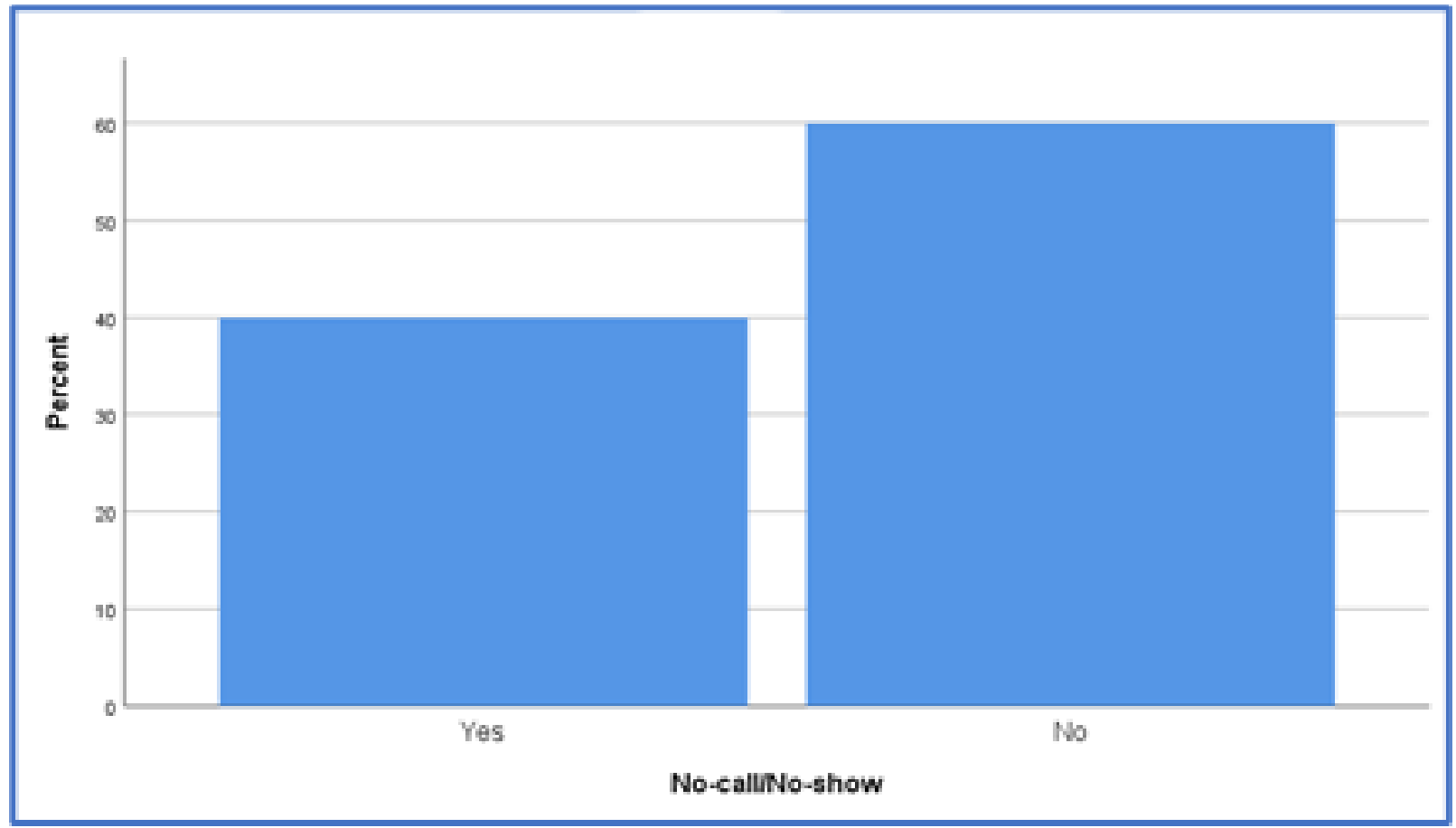




\section{Appendix A}

\section{Hepatitis C Clinic at Milan Puskar Health Right Interview Questionnaire Survey Tool}

\begin{tabular}{|c|c|c|c|c|c|}
\hline Patient age: & \multicolumn{2}{|c|}{ Male } & \multicolumn{3}{|c|}{ Female } \\
\hline Marital status (Circle one) & \multicolumn{2}{|c|}{$\mathrm{M}$} & \multicolumn{2}{|c|}{ W } & $\mathrm{D}$ \\
\hline \multicolumn{6}{|l|}{ Length of time since you were first diagnosed with Hep C? } \\
\hline Employed & \multicolumn{3}{|c|}{ Yes } & \multicolumn{2}{|c|}{ No } \\
\hline 1. Have you ever been referred to a Hepatitis $\mathrm{C}$ clinic in the past? & \multicolumn{3}{|c|}{ Yes } & \multicolumn{2}{|c|}{ No } \\
\hline 2. If so, did you make that appointment? & \multicolumn{3}{|c|}{ Yes } & \multicolumn{2}{|c|}{ No } \\
\hline 3. If you made an appointment, did you keep it? & \multicolumn{3}{|c|}{ Yes } & \multicolumn{2}{|c|}{ No } \\
\hline \multicolumn{6}{|c|}{$\begin{array}{l}\text { 4. Below is a list of possible reasons you did not make or were not able to go to your appointment. } \\
\text { For each problem listed please indicate on a scale of } 1-5 \text { how significant that was to missing your } \\
\text { appointment. } 1=\text { Not at all; } 2=\text { a little; } 3=\text { moderately; } 4=\text { more; } 5=\text { a lot }\end{array}$} \\
\hline Transportation problems & 1 & 2 & 3 & 4 & 5 \\
\hline Forgot & 1 & 2 & 3 & 4 & 5 \\
\hline No insurance & 1 & 2 & 3 & 4 & 5 \\
\hline Copay was too high & 1 & 2 & 3 & 4 & 5 \\
\hline Insurance problems & 1 & 2 & 3 & 4 & 5 \\
\hline Sick on day of appointment & 1 & 2 & 3 & 4 & 5 \\
\hline Fear & 1 & 2 & 3 & 4 & 5 \\
\hline Childcare problems & 1 & 2 & 3 & 4 & 5 \\
\hline Work & 1 & 2 & 3 & 4 & 5 \\
\hline School & 1 & 2 & 3 & 4 & 5 \\
\hline Thought it was a waste of time & 1 & 2 & 3 & 4 & 5 \\
\hline Not satisfied with previous care/treatment & 1 & 2 & 3 & 4 & 5 \\
\hline Language or accessibility needs not met & 1 & 2 & 3 & 4 & 5 \\
\hline You heard from someone else there was nothing that could be done? & 1 & 2 & 3 & 4 & 5 \\
\hline Felt judged or discriminated against & 1 & 2 & 3 & 4 & 5 \\
\hline Other: & & & & & \\
\hline
\end{tabular}

5. What, if anything, could the healthcare system do to help you keep appointment/s at this clinic and any others you may have missed appointments at? 


\section{Appendix B}

Hep C Clinic at Milan Puskar Health Right Log of Appointment Responses

\begin{tabular}{|l|l|l|l|l|l|}
\hline Name (Delete name upon log entry of & Appt Date/Time & $\begin{array}{c}\text { Appt } \\
\text { Kept }\end{array}$ & $\begin{array}{c}\text { Called } \\
\text { to } \\
\text { cancel }\end{array}$ & $\begin{array}{c}\text { Called to } \\
\text { reschedule }\end{array}$ & $\begin{array}{c}\text { No- } \\
\text { call/No- } \\
\text { show }\end{array}$ \\
\hline Deleted & $1 / 17 / 2020$ & & $\mathrm{x}$ & & \\
\hline Deleted & $2 / 14 / 2020$ & & & & $\mathrm{x}$ \\
\hline Deleted & $2 / 14 / 2020$ & & & & $\mathrm{x}$ \\
\hline Deleted & $2 / 21 / 2020$ & & & & \\
\hline Deleted & $2 / 28 / 2020$ & $\mathrm{x}$ & & & $\mathrm{x}$ \\
\hline Deleted & $3 / 6 / 2020$ & & & & \\
\hline Deleted & $3 / 13 / 2020$ & $\mathrm{x}$ & & & \\
\hline
\end{tabular}


Appendix C

\section{Letter of Permission to Conduct Research}

I, Laura Jones, Executive Director, give my permission for Susan McKenrickto conduct her study entitled Integrating Care: Evaluation of a Hepatitis C Clinic Co-located with Harm Reduction and Addiction Treatment Programs in a Rural Clinicat Milan Puskar Health Right, 341 Spruce St, Morgantown, WV 26505

Signature of Location Administrator

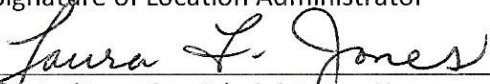

Printed Location Administrajor Name

Laura Jones

Date

October 21, 2019 


\section{Appendix D}

\section{HCV Patient Labs/Studies Checklist}

Note: This is a list of what is standard for new HCV patient evaluation (it's the checklist I use). With the removal of the liver fibrosis restriction imposed by Medicaid, we usually will not need a Fibrosure test or ultrasound, unless the patient has RUQ pain, jaundice, significantly elevated liver enzymes, or other $\mathrm{s} / \mathrm{s}$ of liver damage.

1. Confirm infection status with PCR RNA Quantitative with reflex to genotype

Once infection status is confirmed - IF patient is being seen by PCP and getting labs prior to HCV Clinic, it would be great if these could be included. Otherwise, I will order at time of visit.

2. Other pre-treatment labs (lipids and Fibrosure are 8-hour fasting labs):
a. $\mathrm{CBC} /$ diff
b. $\mathrm{BUN} / \mathrm{Cr}$
c. AST, ALT, Alk phos
d. Iron, Transferrin, Ferritin, and TIBC
e. Total and calculated bili
f. Albumin
g. PTT, PT/INR (Check with Emily)
h. Vitamin D
i. HCV Genotype (if not already done)
j. Liver Fibrosis (Fibrosure) Ask - may not be necessary for all patients Ruby: 1237128 (8 hour fasting) Mon Gen (LabCorp): 550123 (8 hour fasting)
k. Anti-Hep A IGG, Hep A IgM Ab is important to confirm no active Hep B infection - HCV treatment can cause a flareup of symptoms
l. Hep B Surface Ab, Hep B surface antigen, Hep B total core Ab (Anti-HBc) - this
m. A1C
n. Consider lipid panel

3. Imaging - Elastography $(\mathrm{CPT}=91200) \quad \boldsymbol{O} \boldsymbol{R} \quad$ RUQ US $(\mathrm{CPT}=76705)$ as needed

4. PHQ9 Patient Health Questionnaire tool for depression

5. Assess for and immunize as appropriate for:
a. Hep A
b. Hep B
c. Pneumovax
d. Tdap 


\section{Appendix E}

\begin{tabular}{|c|c|c|c|c|c|}
\hline \multicolumn{6}{|c|}{ Budget } \\
\hline \multicolumn{3}{|l|}{ Clinic Items } & Projected Cost & $\begin{array}{c}\text { Actual } \\
\text { Cost }\end{array}$ & Difference \\
\hline \multicolumn{3}{|c|}{$\begin{array}{l}\text { Administrative: Nurse Practitioner (Project Coordinator) time }= \\
\$ 50 / \mathrm{hr} \times 4 \mathrm{hrs} / \text { week } \times 12 \text { weeks }=\$ 2400 \text { clinical time, } \$ 50 / \text { hour } \\
\text { x } 10 \text { hours for preparation of materials, staff education } \\
\text { Support staff cost absorbed by organization (no additional staff } \\
\text { required at this time) }\end{array}$} & $\$ 2900$ & $\$ 2900$ & $\$ 0$ \\
\hline \multicolumn{3}{|c|}{$\begin{array}{l}\text { Educational Materials (Flyers for patients, Ppt handouts for } \\
\text { staff, CE/certificate) }\end{array}$} & $\$ 50$ & $\$ 10$ & $+\$ 40$ \\
\hline \multicolumn{3}{|c|}{ Project supplies (Office supplies, copy paper) } & $\$ 25$ & $\$ 10$ & $+\$ 15$ \\
\hline \multicolumn{3}{|c|}{ Facilities (Contributed by organization) } & $\$ 0$ & $\$ 0$ & $\$ 0$ \\
\hline \multicolumn{3}{|c|}{ Hospitality (Lunch for 10 staff on education day X \$15/pp) } & $\$ 150$ & $\$ 123$ & $+\$ 27$ \\
\hline \multicolumn{3}{|c|}{ Travel (N/A - travel is within author's normal driving distance) } & $\$ 0$ & $\$ 0$ & $\$ 0$ \\
\hline \multicolumn{3}{|c|}{$\begin{array}{l}\text { Incentive (small token for questionnaire completion by known } \\
\text { HCV positive patients - \$2/each for } 50 \text { questionnaires) }\end{array}$} & $\$ 100$ & $\$ 25$ & $+\$ 75$ \\
\hline \multicolumn{3}{|l|}{ Unanticipated expenses } & $\$ 50$ & $\$ 0$ & $+\$ 50$ \\
\hline \multicolumn{3}{|c|}{ Marketing (Flyers to post in clinic-cost covered under supplies) } & $\$ 0$ & $\$ 0$ & $\$ 0$ \\
\hline \multicolumn{3}{|l|}{ Total } & $\$ 3,275$ & $\$ 3068$ & $+\$ 207$ \\
\hline $\begin{array}{l}\text { Projected Income Source } \\
\text { WVCTSI Small Grant }\end{array}$ & Amount & \multirow{6}{*}{\multicolumn{4}{|c|}{$\begin{array}{l}\text { Additional budget comments: } \\
\text { - MPHR is funded by grants and donations. Hourly wage based } \\
\text { on the US Bureau of Labor and Statistics average NP wage for } \\
\text { West Virginia (U.S. Bureau of Labor Statistics, 2018) } \\
\text { - Patient gifts were purchased as appreciation for completing a } \\
\text { questionnaire. } \\
\text { - Facilities are already operational with all necessary equipment } \\
\text { and software. Student will use personal computer equipped } \\
\text { with Excel to create and maintain deidentified tracking log } \\
\text { - This location already has clinics servicing patients, a } \\
\text { concurrent 4-hour clinic should not add an undue burden to } \\
\text { current staff } \\
\text { Met with WVCTSI staff member on 7/16/19 - was encouraged } \\
\text { to apply for a grant; however, the time frame to apply for a } \\
\text { grant to use in the projected time frame for this project had } \\
\text { passed. Time and money donated by author kept cost within } \\
\text { budget. }\end{array}$}} \\
\hline Personal funds & $\$ 200$ & & & & \\
\hline Other & $\$ 0$ & & & & \\
\hline Total projected income & $\$ 5,200$ & & & & \\
\hline Total actual income & $\$ 3100$ & & & & \\
\hline Total actual cost & $\begin{array}{r}\frac{-\$ 3068}{+\$ 32} \\
\end{array}$ & & & & \\
\hline
\end{tabular}




\section{Appendix F}

\section{Milan Puskar Health Right Hepatitis C Clinic - Getting started checklist}

Meet with key leaders and sign agreement with Milan Puskar Health Right

Start credentialing with MPHR

Copy of malpractice insurance from Toni Dichiacchio

CAQH ProView Updated and attested

Notify WVBON - Prescribing

Education/in-service with MPHR staff

Review paperwork - checklists, phone triage, intake form

DNP Student to orient to MPHR EHR System

DNP Student to orient to workflow at MPHR

Set up exam room (exam table, chair, otoscope, reflex hammer, tongue blades)

Set up desk space (office supplies as needed)

$=$ Completed prior to January 17, $2020-$ the first day of clinic 


\section{Appendix G}

Staff Education Pre and Post Test

1. Hepatitis $\mathrm{C}$ is a systemic disease?

True

False

2. A DAA is:
a. A direct acting antiviral
b. A direct antiviral agent
c. A decreased antiviral account
d. None of the above

3. Drug manufacturers do not provide medications to needy patients. True False

4. When patients call to ask questions about the Hepatitis C/clinic I should....
a. Tell them, "I can't answer any questions" and they should just make an appointment
b. Refer to the Phone Triage form to find answers to the most common questions
c. Tell the patient I don't know the answer but I can find out and get back to them
d. $b$ and $c$

5. The new patient intake questionnaire-

a. is for patients who already come to Milan Puskar Health Right for their primary care

b. is for all patients who are being seen in the Hepatitis $\mathrm{C}$ clinic for the first time

c. does not need completed if patient is already established at Milan Puskar Health Right

d. must be completed by a nurse

6. Medicaid does not cover treatment for Hepatitis C

True

False

7. Prior authorization can be obtained by - select all that apply
a. a nurse practitioner
b. a medical assistant (MA)
c. an LPN
d. specialty pharmacy
e. all of the above 


\section{Appendix H}

\section{Staff Satisfaction Questionnaire (Anonymous)}

\begin{tabular}{|l|l|l|l|l|l|}
\hline Please circle your response: \\
1=Very satisfied 2=Satisfied 3=Neutral 4=Dissatisfied 5=Very dissatisfied \\
\hline $\begin{array}{l}\text { The educational program helped me feel prepared for this clinic. } \\
\text { The Phone Triage flyer helped me answer questions when patients called. }\end{array}$ & $\mathbf{1}$ & $\mathbf{2}$ & $\mathbf{3}$ & $\mathbf{4}$ & $\mathbf{5}$ \\
\hline $\begin{array}{l}\text { The education program helped me feel more confident about using patient } \\
\text { assistance programs for HCV medications }\end{array}$ & $\mathbf{1}$ & $\mathbf{2}$ & $\mathbf{3}$ & $\mathbf{4}$ & $\mathbf{5}$ \\
\hline $\begin{array}{l}\text { The learning objectives (disease process, fielding phone question, anticipated } \\
\text { lab and imaging tests, assistance programs) were met }\end{array}$ & $\mathbf{1}$ & $\mathbf{2}$ & $\mathbf{3}$ & $\mathbf{4}$ & $\mathbf{5}$ \\
\hline
\end{tabular}

Comments:

What would improve your confidence in managing HCV patients at MPHR? 


\section{Appendix I}

Hepatitis C Clinic at Milan Puskar Health Right Implementation/Feasibility Survey Tool

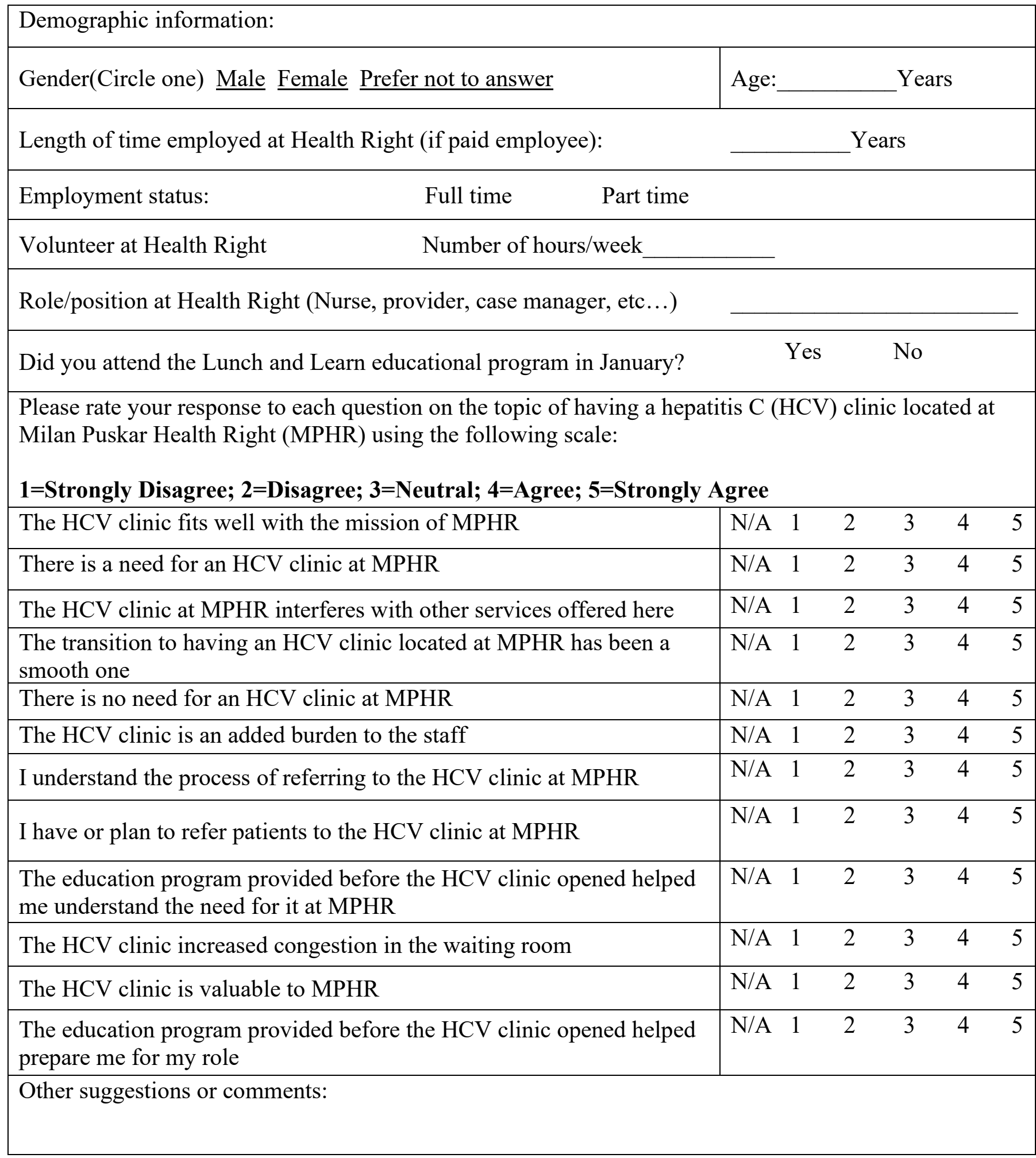




\section{Appendix J}

From: Danielle

Sent: Friday, April 10, 2020 1:54 PM

To: McKenrick, Susan

Subject: Re: Question for you

Just reading that made my heart melt and tears to my eyes! You just don't know how grateful I am for you! Thanks for adding me to your project! The love I have for you is unconditional and true.

Much love my dear friend,

Dani

On Thu, Apr 9, 2020 at 5:48 PM McKenrick, Susan wrote:

Hi Dani,

I will be presenting my DNP project next week and I am finally finishing up my paper. Below is my acknowledgment page - I wanted to share it with you and make sure you are OK with your name being in it.

Hugs,

Sue

Susan R. McKenrick, MSN, APRN, FNP-BC, DNP2B

Clinical Assistant Professor

WVU School of Nursing

6600 Health Sciences Center

Post Office Box 9600

Morgantown, WV 26506-9602

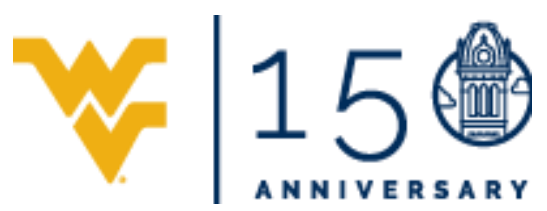

